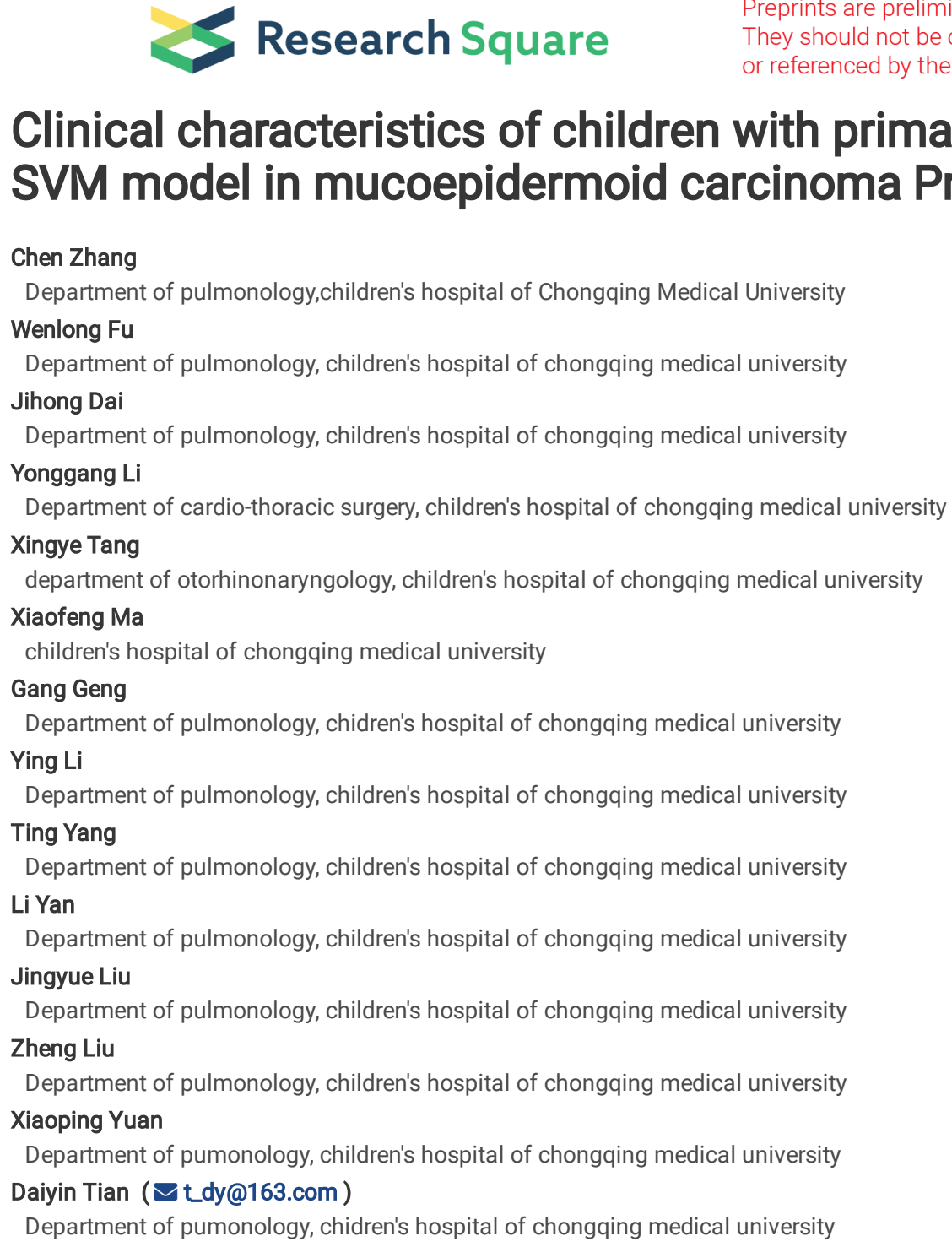

\title{
Clinical characteristics of children with primary tracheobronchial tumors and SVM model in mucoepidermoid carcinoma Prediction
}

\section{Research article}

Keywords: tracheobronchial tumors, children, bronchoscopy, clinical characteristics, SVM model

Posted Date: November 20th, 2020

DOI: https://doi.org/10.21203/rs.3.rs-111381/v1

License: (a) (i) This work is licensed under a Creative Commons Attribution 4.0 International License. Read Full License 


\section{Abstract \\ Objective}

To determine the clinical characteristics, treatment, and prognosis of primary tracheobronchial tumors (PTT) in children.

\section{Methods}

The medical records of children with PTT who were hospitalized at the Children's Hospital of Chongqing Medical University from January 1995 through January 2020 were reviewed retrospectively. The clinical features, imaging, and bronchoscopic manifestations, treatment, and outcomes of these patients were summarized.

\section{Results}

Sixteen children were hospitalized with PTT during the study period: five (31.3\%) with mucoepidermoid carcinoma (ME), three (18.8\%) with inflammatory myofibroblastic tumors (IMT), two (12.5\%) with sarcoma, two (12.5\%) with papillomatosis, and one (6.3\%) each with carcinoid carcinoma, adenoid cystic carcinoma (ACC), hemangioma, and schwannoma. Among them, ME was the most common type of tumor, and we used some statistical and machine learning techniques to predict ME, such as Gaussian naïve Bayes model, SVM(support vector machine) model, and decision tree model. The median age at diagnosis of PPTs was 9.3 years (range, 3-15 years), and the main clinical symptoms were cough (81.3\%), breathlessness (50\%), wheezing (43.8\%), progressive dyspnea (37.5\%), hemoptysis (37.5\%), and fever (25\%). The most frequent complication on chest imaging was atelectasis (56.3\%), followed by bronchiectasis (25\%) and emphysema (12.5\%). Of the 16 patients, seven underwent surgical treatment, eight underwent bronchoscopic tumor resection, and one died. Of the 11 children followed-up, three experienced recurrence, including two who underwent subsequent tracheotomies, both of whom have varying degrees of post-activity shortness of breath. The other eight patients did not experience recurrence. No deaths were observed during follow-up.

\section{Conclusion}

PTTs are very rare in children, with ME having the highest incidence. And the SVM model showed high accuracy with respect to identifying ME. Chest CT and bronchoscopy can diagnose PTT effectively. Surgery is the treatment of choice, although bronchoscopic intervention can achieve good results in patients with unresectable tumors. The prognosis of the 11 followed-up children was good.

\section{Introduction}

Primary tracheobronchial tumors (PTT) are extremely rare in children and are misdiagnosed easily. Few reports describe patients with these tumors, making their clinical presentation, diagnosis, treatment, and outcome unclear. This study retrospectively reviewed the clinical data of children who were hospitalized with pathologically confirmed PTT in the Children's Hospital of Chongqing Medical University from January 1995 to January 2020 , and then followed-up by telephone in July 2020.

\section{Materials And Methods}

The medical records of all children diagnosed with PTT from January 1995 to January 2020 at the respiratory department, thoracic surgery ward, and ear, nose, and throat department of the Children's Hospital of Chongqing Medical University were reviewed retrospectively. Data collected included demographic characteristics, clinical presentation, results of chest X-rays and computed tomography (CT) scans, pathological diagnosis, lesion location, treatment, followup, and clinical outcome. Patients were included if they were under 18 years old and had an intracavitary lesion of the trachea or large bronchus confirmed by chest CT and bronchoscopy, with pathology confirmed by biopsy ${ }^{1,2}$. Patients with lung cancer, laryngeal cancer, and metastatic tracheobronchial tumors were excluded. At the same time, the clinical manifestations and imaging characteristics collected were used to establish a database to construct an identification model for the most common tracheobronchial tumor type, ME. We use Gaussian naïve Bayes model, SVM(support vector machine) model, and decision tree model to build the model respectively.

\section{Results}

\subsection{General information}

During the study period, 16 children (ten boys and six girls; median age, 9.3 years; range, $3-15$ years) were diagnosed with PTT. Of these, ten were aged between 9 and 15 years. Five (31.3\%) had mucoepidermoid carcinomas (ME), three (18.8\%) had inflammatory myofibroblastic tumors (IMT), two (12.5\%) had sarcomas, two (12.5\%) had papillomatosis, and one (6.3\%) each had carcinoid carcinoma, adenoid cystic carcinoma (ACC), hemangioma, and schwannoma (Tables 1 and 2). The personal and family histories of the 16 children were unremarkable.

\subsection{Clinical manifestations}

The main clinical manifestations in these 16 children were cough (81.3\%), breathlessness (50\%), wheezing (43.7\%), progressive dyspnea (37.5\%), hemoptysis (37.5\%), and fever (25\%) (Table 3). Other manifestations included chest pain, weight loss, hoarseness, and dysphagia. The average delay between symptom 
appearance and initial diagnosis was 10 months (range, 7 days to 5 years). Tumors located in the trachea usually presented with dyspnea, hoarseness, dysphagia, or other neck compression symptoms (dyspnea occurred earlier than bronchial tumors).

\subsection{Radiological examination}

Most of these children underwent chest CT with enhancement and airway reconstruction, with chest CT usually showing bronchial luminal obstruction in the lesion, with soft tissue shadowing, with or without bronchiectasis, atelectasis, or compensatory emphysema (Fig. 1). The most common abnormalities were atelectasis $(9 / 16,56.3 \%)$, followed by bronchiectasis $(4 / 16,25 \%)$ and emphysema $(2 / 16,12.5 \%)$. Maximum tumor diameter ranged from 5 to 40 mm. Seven tumors were located in the left main bronchus, three in the right main bronchus, and six in the trachea. PET/CT scanning of one patient with ME (moderately malignant) and carcinoid carcinoma revealed an SUV in the primary lesion that was significantly higher than that in the surrounding tissue, which is consistent with manifestations of a malignant tumor. F-18 FDG accumulation in the lesion has been reported in high-and low-grade MEs ${ }^{3}$.

\subsection{Diagnosis and treatment}

Fifteen children underwent bronchoscopy and biopsy. Seven were treated surgically. Three (19\%) underwent sleeve lobectomies: two underwent left upper sleeve lobectomies, and one underwent a right middle sleeve lobectomy. In addition, one (6\%) patient underwent a right middle and lower lobectomy, and three (19\%) underwent tracheal sleeve lobectomies with end-to-end anastomosis, including one who also underwent partial thyroidectomy. The remaining eight children underwent local tumor resection via bronchoscopy: five (31\%) underwent tumor resection alone, and two (13\%) underwent tumor resection followed by chemotherapy. Surgery was successful in all 15 patients.

One child died during hospitalization due to sudden onset of extreme dyspnea. Bronchoscopy revealed complete obstruction of the left main bronchus and two-thirds of the right bronchus by the tumor. An autopsy confirmed the diagnosis of rhabdomyosarcoma.

\subsection{Follow-up and outcome}

Of the 15 children, two were lost to follow-up after 5 and 60 months, and four were never followed-up. The remaining nine children were reached successfully by telephone in July 2020. The average follow-up duration was 46 months (range, 5-182 months). One child (patient no. 3) experienced tumor recurrence within 2 months after tracheal sleeve resection; this patient underwent local tumor resection twice, with no recurrence for 18 months thereafter. However, this patient still experiences wheezing after strenuous activity. Two children with intratracheal papillomatosis (patient nos. 13 and 14) experienced tumor recurrence 6-8 times and underwent repeated local tumor resection, with no new recurrence at the last follow-up. One still experiences shortness of breath after activity, whereas the other can participate in normal activities; both have hoarseness. Two patients (patient nos. 2 and 4 ) who underwent local tumor resection plus chemotherapy are still receiving chemotherapy, with patient number 2 being treated with ifosfamide, etoposide, vindesine, methotrexate, and prednisone; their activities are not affected. The remaining children show no evidence of disease recurrence. No deaths were observed during the follow-up period.

\subsection{Recognition model of ME}

ME carcinoma was the most common tracheobronchial tumor in children. A total of 16 characteristic parameters were selected to construct a database: ten clinical manifestations (cough, fever, progressive dyspnea, weight loss, wheezing, dysphagia, breathlessness, hemoptysis, chest pain, and hoarseness); three tumor locations (left bronchus, right bronchus, and trachea); and three imaging features (atelectasis, bronchiectasis, and emphysema). Then, a Gaussian naïve Bayes model, an SVM model, and a decision tree model were used to predict incidence of mucoepidermoid carcinoma (Table 4). All cases were assigned randomly to a training set (11 cases) and a test set (five cases). The training set was used to select characteristics and to construct recognition models, and the test set was used to evaluate the prediction performance of the models. The area under the ROC curve (AUC), accuracy, and F1-score were used to evaluate the models. We found that the SVM model showed the best performance, followed by the decision trees and the Gaussian plain Bayes model. The SVM model uses python sklearn, and the kernel is linear; the relaxation coefficient is 6.13 , and the other parameters are default settings. The accuracy, AUC, and F1-score of the test set were all 1 (Fig. 2), which indicates that the model shows good predictive efficiency in the test set. 
Table 1

Clinical profiles and outcomes of 16 patients with primary tracheobronchial tumors

\begin{tabular}{|c|c|c|c|c|c|c|c|c|c|}
\hline $\begin{array}{l}\text { Patient } \\
\text { no. }\end{array}$ & Age/sex & Symptoms & $\begin{array}{l}\text { Symptom } \\
\text { duration } \\
\text { (months)* }\end{array}$ & Pathology & Location & Size (mm) & $\begin{array}{l}\text { Imaging } \\
\text { characteristics }\end{array}$ & $\begin{array}{l}\text { Treatment } \\
\text { methods }\end{array}$ & $\begin{array}{l}\text { Follow- } \\
\text { up } \\
\text { (months) }\end{array}$ \\
\hline 1 & 4/B & $\begin{array}{l}\text { Cough, fever, } \\
\text { dyspnea, } \\
\text { weight loss }\end{array}$ & 0.4 & IMT & LM & $16.3 * 4$ & Atelectasis & $\begin{array}{l}\text { Upper sleeve } \\
\text { lobectomy }\end{array}$ & 48 \\
\hline 2 & $5 / B$ & $\begin{array}{l}\text { Cough, fever, } \\
\text { wheezing }\end{array}$ & 1 & IMT & LM & $26.8 * 10.2$ & $\begin{array}{l}\text { Atelectasis, } \\
\text { bronchiectasis }\end{array}$ & $\begin{array}{l}\text { Tumor } \\
\text { resection + } \\
\text { chemotherapy }\end{array}$ & 6 \\
\hline 3 & $11 / B$ & $\begin{array}{l}\text { Dyspnea, } \\
\text { dysphagia }\end{array}$ & 4 & IMT (ALK positive) & $\mathrm{T}$ & $18.4^{\star} 16.5^{\star} 14.5$ & No & $\begin{array}{l}\text { Trachea } \\
\text { sleeve } \\
\text { resection }\end{array}$ & 22 \\
\hline 4 & $12 / \mathrm{B}$ & $\begin{array}{l}\text { Cough, } \\
\text { wheezing, } \\
\text { breathlessness }\end{array}$ & 2 & $\begin{array}{l}\text { ME (moderate } \\
\text { malignancy) }\end{array}$ & LM & $25.4 * 13.2 * 12.8$ & $\begin{array}{l}\text { Atelectasis, } \\
\text { emphysema }\end{array}$ & $\begin{array}{l}\text { Tumor } \\
\text { resection }+ \\
\text { chemotherapy }\end{array}$ & 5 \\
\hline 5 & $10 / G$ & $\begin{array}{l}\text { Cough, } \\
\text { wheezing, } \\
\text { breathlessness, } \\
\text { hemoptysis }\end{array}$ & 10 & $\begin{array}{l}\text { ME (low-grade } \\
\text { malignancy) }\end{array}$ & RM & $23.8 * 19.2 * 40.6$ & Emphysema & $\begin{array}{l}\text { Tumor } \\
\text { resection }\end{array}$ & 16 \\
\hline 6 & $9 / \mathrm{B}$ & $\begin{array}{l}\text { Cough, fever, } \\
\text { breathlessness, } \\
\text { dyspnea }\end{array}$ & 1 & $\begin{array}{l}\text { ME (low-grade } \\
\text { malignancy) }\end{array}$ & LM & $13 * 16 * 12$ & $\begin{array}{l}\text { Atelectasis, } \\
\text { bronchiectasis }\end{array}$ & $\begin{array}{l}\text { Tumor } \\
\text { resection }\end{array}$ & 44 \\
\hline 7 & $14 / B$ & $\begin{array}{l}\text { Cough, } \\
\text { breathlessness, } \\
\text { hemoptysis }\end{array}$ & 60 & $\begin{array}{l}\text { ME (low-grade } \\
\text { malignancy) }\end{array}$ & LUL & $35 * 25$ & $\begin{array}{l}\text { Atelectasis, } \\
\text { emphysema, } \\
\text { bronchiectasis }\end{array}$ & $\begin{array}{l}\text { Upper sleeve } \\
\text { lobectomy }\end{array}$ & lost \\
\hline 8 & 9/B & $\begin{array}{l}\text { Cough, } \\
\text { hemoptysis }\end{array}$ & 5 & ME & RIL & $37.5^{\star} 16.3^{*} 17.4$ & Atelectasis & $\begin{array}{l}\text { Middle sleeve } \\
\text { lobectomy }\end{array}$ & lost \\
\hline 9 & $13 / G$ & $\begin{array}{l}\text { Cough, } \\
\text { wheezing, } \\
\text { breathlessness, } \\
\text { hemoptysis }\end{array}$ & 24 & Carcinoid & RIL & $7.3 * 22.6$ & Atelectasis & $\begin{array}{l}\text { Middle and } \\
\text { lower } \\
\text { lobectomy }\end{array}$ & 19 \\
\hline 10 & $13 / B$ & $\begin{array}{l}\text { Cough, fever, } \\
\text { wheezing, } \\
\text { breathlessness, } \\
\text { dyspnea }\end{array}$ & 1 & ACC & $\mathrm{T}$ & $13.2 * 11.5 * 24.7$ & Bronchiectasis & $\begin{array}{l}\text { Trachea } \\
\text { sleeve } \\
\text { resection }\end{array}$ & lost \\
\hline 11 & 15/B & $\begin{array}{l}\text { Cough, } \\
\text { breathlessness, } \\
\text { hemoptysis, } \\
\text { chest pain }\end{array}$ & 1 & Schwannoma & $\mathrm{T}$ & $12.7 * 8.2$ & No & $\begin{array}{l}\text { Trachea } \\
\text { sleeve } \\
\text { resection + } \\
\text { right partial } \\
\text { thyroidectomy }\end{array}$ & 25 \\
\hline 12 & $8 / G$ & $\begin{array}{l}\text { Cough, } \\
\text { hemoptysis }\end{array}$ & 0.2 & Hemangioma & $\mathrm{T}$ & $5 \star 3.6$ & No & $\begin{array}{l}\text { Tumor } \\
\text { resection }\end{array}$ & 76 \\
\hline 13 & $3 / G$ & $\begin{array}{l}\text { Hoarseness, } \\
\text { dyspnea }\end{array}$ & 24 & Papillomatosis & $\mathrm{T}$ & $10 * 10 * 10$ & No & $\begin{array}{l}\text { Tumor } \\
\text { resection }\end{array}$ & 60 \\
\hline 14 & 4/B & $\begin{array}{l}\text { Wheezing, } \\
\text { breathlessness }\end{array}$ & 24 & Papillomatosis & $\mathrm{T}$ & $10 * 5$ & Atelectasis & $\begin{array}{l}\text { Tumor } \\
\text { resection }\end{array}$ & 182 \\
\hline 15 & $6 / G$ & $\begin{array}{l}\text { Cough, } \\
\text { wheezing, } \\
\text { breathlessness, } \\
\text { dyspnea }\end{array}$ & 1 & Rhabdomyosarcoma & LM & $20 * 18$ & Atelectasis & Dead & \\
\hline 16 & $13 / G$ & $\begin{array}{l}\text { Cough, } \\
\text { hemoptysis, } \\
\text { chest pain }\end{array}$ & 6 & Synovial sarcoma & RM & $7.7 * 16.6$ & No & $\begin{array}{l}\text { Tumor } \\
\text { resection }\end{array}$ & lost \\
\hline
\end{tabular}

Abbreviations: G, girl; B, boy; ME, mucoepidermoid tumor; ACC, adenoid cystic carcinoma; IMT, inflammatory myofibroblastic tumor; ALK, anaplastic lymphom stem bronchus; LUL, left upper lobe; RM, right main stem bronchus; RIL, right intermiddle lobe; T, trachea; NED, no evidence of disease.

*Time from symptom appearance to initial diagnosis. 
Table 2

Characteristics of the various types of tracheobronchial tumor

\begin{tabular}{|c|c|c|c|c|c|c|c|c|c|}
\hline \multirow[t]{2}{*}{ Pathological types[2] } & \multicolumn{4}{|c|}{ Malignant tumors } & \multicolumn{4}{|c|}{ Benign tumors } & \multirow[t]{2}{*}{ Total } \\
\hline & ME & Sarcoma & $\mathrm{ACC}$ & Carcinoid & IMT & Papillomatosis & Schwannoma & Hemangioma & \\
\hline Number of patients & 5 & 2 & 1 & 1 & 3 & 2 & 1 & 1 & 16 \\
\hline Left bronchus /trachea/right bronchus & $3 / 0 / 2$ & $1 / 0 / 1$ & $0 / 1 / 0$ & $0 / 0 / 1$ & $2 / 1 / 0$ & $0 / 2 / 0$ & $0 / 1 / 0$ & $0 / 1 / 0$ & $7 / 6 / 3$ \\
\hline $\operatorname{Sex}(B / G)$ & $4 / 1$ & $0 / 2$ & $1 / 0$ & $0 / 1$ & $3 / 0$ & $1 / 1$ & $1 / 0$ & $0 / 1$ & $10 / 6$ \\
\hline Average age (year) & 10.8 & 9.5 & 13 & 13 & 6.7 & 3.5 & 15 & 8 & 9.3 \\
\hline Atelectasis & 4 & 1 & 0 & 1 & 2 & 1 & 0 & 0 & 9 \\
\hline Death & 0 & 1 & 0 & 0 & 0 & 0 & 0 & 0 & 1 \\
\hline Recurrence & 0 & 0 & 0 & 0 & 1 & 2 & 0 & 0 & 3 \\
\hline Follow-up & 3 & 0 & 0 & 1 & 3 & 2 & 1 & 1 & 11 \\
\hline
\end{tabular}

Table 3

Main symptoms presenting in the 16

pediatric patients with

tracheobronchial tumors

\begin{tabular}{|ll|}
\hline Symptoms & $\mathbf{n = 1 6 ( \% )}$ \\
\hline Cough & $13(81.3 \%)$ \\
\hline Breathlessness & $8(50 \%)$ \\
\hline Wheezing & $7(43.8 \%)$ \\
\hline Progressive dyspnea & $6(37.5 \%)$ \\
\hline Hemoptysis & $6(37.5 \%)$ \\
\hline Fever & $4(25 \%)$ \\
\hline Chest pain & $2(12.5 \%)$ \\
\hline Dysphagia & $1(6.3 \%)$ \\
\hline Weight loss & $1(6.3 \%))$ \\
\hline Hoarseness & $1(6.3 \%)$ \\
\hline Asymptomatic & 0 \\
\hline
\end{tabular}

Table 4

Evaluation index of the three models

\begin{tabular}{|llll|}
\hline Measure & Gauss naïve Bayes & Support vector machine(linear) & Decision trees \\
\hline Accuracy & 0.60 & 1.00 & 0.80 \\
\hline F1-score & 0.60 & 1.00 & 0.78 \\
AUC & 0.58 & 1.00 & 0.75 \\
\hline AUC, area under the ROC curve. F1-score is a weighted average of the precision and recall. \\
\hline
\end{tabular}

\section{Discussion}

PTTs are very rare in children. Here, we found that the incidence of tumors in pre-school or school-age children was higher in boys than in girls, and that the most common tumor was ME (31.3\%). Different from the most common types of tumor reported abroad ${ }^{5}$, ME carcinoma is the most common type of PTT reported in domestic studies, even accounting for up to $74 \%$ of cases ${ }^{4}$. Thus, ME is a malignant tumor with a high incidence rate, meaning that identification is important. The SVM model showed high accuracy with respect to identifying ME. Therefore, in the absence of invasive pathological biopsy, the model can be used to analyze clinical data from patients with tracheobronchial tumors and can help to identify the typeof the tumor; this will be especially useful for young doctors or doctors in primary hospitals as it provides an important reference for follow-up treatment and clinical research. However, in view of the small number of cases in our group, the model shows some instability and requires further verification using other independent data.

No specific respiratory symptoms are present during the early stage of the PPTs ${ }^{6}$. In our cohort, the most common symptom was a cough, followed by breathlessness, wheezing, progressive dyspnea, and fever. The incidence of specific symptoms such as hemoptysis and chest pain is similar in children and adults ${ }^{4}$, whereas non-specific symptoms such as fever, cough, and wheezing are more common in children. X-rays of the 16 children identified lung infection in seven. The remaining nine were negative, resulting in misdiagnoses that included pneumonia, asthma, or foreign bodies, with one child being misdiagnosed 
with tuberculosis for 5 years. Finally, these children were diagnosed with PTT by chest CT and bronchoscopy. The rate of misdiagnosis of PTTs has decreased gradually over time, as has the time from appearance of symptoms to a correct diagnosis; this is due to greater use of chest CT and bronchoscopy. Chest CT can assess the size and location of the lesion, the extent of infiltration into surrounding tissues, the enlargement of mediastinal lymph nodes, and the involvement of the lung parenchyma ${ }^{6,7}$. The high calcification rate $(50 \%)$ seen in $\mathrm{ME}^{8}$ can be confirmed by CT. Bronchoscopy can visualize the site, shape, and size of the lesion, enabling biopsies to determine the nature of the lesion; however, the positivity rate of bronchial lavage is low ${ }^{9}$.

Surgery is the treatment of choice for PTT in children, with sleeve lobectomy often chosen to preserve lung function ${ }^{4-6}$. Complete surgical resection is effective in patients with malignant tumors ${ }^{10}$; however, the benefits of adjuvant radiotherapy and chemotherapy are unclear, so they are used rarely. Chemotherapy and radiotherapy are still recommended for children with tumor recurrence ${ }^{7}$, and radiotherapy is a viable option for patients with highly malignant tumors with positive surgical margins ${ }^{11}$. Studies of targeted therapy for PTT show that recurrent respiratory papillomatosis responds well to bevacizumab ${ }^{12}$. In addition, adjuvant treatment with an ALK inhibitor such as cyclozolidinib improves the prognosis of children with IMT and partial ALK gene rearrangement ${ }^{13-15}$

In addition to surgical resection, bronchoscopic intervention is effective in treating patients with PTT ${ }^{9}$. However, the benefits of endoscopic local resection of tumors are unclear because endoscopic resection has several limitations, including a high risk of transmural injury, an inability to coagulate larger diameter vessels, and a risk of airway tree dislocation ${ }^{16}$. CT angiography before fibrilloscopic intervention showed that two patients in the present cohort had large vessels deep within the tumor. After consultation with a cardiologist to reduce the risk of bleeding, both patients underwent minimally invasive vessel closure. In addition to the higher intraoperative risk, the recurrence rate was higher after local resection than after surgical treatment. Indeed, $43 \%$ of patients who underwent local resection experienced tumor recurrence during follow-up period ${ }^{4}$. Because some of these patients later required tracheal cricotomy, single local tumor resection through bronchoscopy is not recommended. At present, bronchoscopy is used mainly to assess the degree of airway narrowing, to take biopsies to confirm the diagnosis, and to perform temporary palliative treatment such as deburring, lavage, or APC plus cryotherapy ${ }^{7}$ in patients with unresectable lesions, both to reduce airway obstruction and improve patient quality of life.

Factors affecting the prognosis of children with PTT include histologic classification, pathologic grade, tumor size, lymph node status, distant metastasis, and the extent and ability of surgery ${ }^{17-19}$, with pathologic type being the most important factor ${ }^{19}$. For example, ME (the most common type of PTT) can be classified as low, intermediate, and high-grade tumors ${ }^{20,21}$. The Adult Tracheobronchial ME Study reported that the 5 year survival rate of patients with lowgrade ME was $57 \%$, whereas the survival rate of patients with high-grade ME was significantly lower ${ }^{21,22}$, with a 1 year survival rate of only $20 \%{ }^{18}$. Moreover, survival rates differed significantly in patients who did and did not undergo surgery. By contrast, the 5 year survival rate of children with ME is estimated to be 95\%; no deaths were reported in children with low- to intermediate-grade ME, with those having high-grade ME or distant metastases having a lower survival rate. The presence of a $\mathrm{t}(11 ; 19)(\mathrm{q} 21 ; \mathrm{p} 13)$ translocation is also associated with a good prognosis in children ${ }^{18}$. Chemotherapy is associated with poorer late health and lower long-term survival rates ${ }^{23}$. Except for one child in our cohort who was diagnosed with sarcoma and died during hospitalization, the prognosis of the 11 children who were followed-up was good. Three patients experienced tumor recurrence, with two undergoing subsequent tracheotomy. Their prognosis, however, remained good after a maximum follow-up of 182 months. The other eight patients, including three treated surgically and five treated by bronchial intervention, did not experience tumor recurrence after a maximum follow-up of 76 months. Guidelines suggest that bronchoscopy should be performed every 6 months for the first year and then annually thereafter ${ }^{24}$.

In summary, pediatric PTT is relatively rare, with an insidious onset and an uncharacteristic clinical presentation 6,7 . Increased tumor volume may cause tracheal and bronchial lumen narrowing and, when combined with respiratory tract infection, can result in fever, cough, breathlessness, and wheezing. These conditions can be confused easily with bronchial foreign body, asthma, pneumonia, and other bronchial diseases, leading to an incorrect or missed diagnosis $8,25,26$. Lack of realization of the possibility of a tumor and the consequent need for chest CT and bronchoscopy can delay treatment, resulting in extensive adhesions and involvement of surrounding tissues, or even spread to distant airways, thereby worsening the prognosis ${ }^{13,15}$. PTT should be considered in patients with chronic cough, wheezing, or progressive dyspnea who respond poorly to conventional treatment. A thorough examination of the respiratory tract, especially chest CT and bronchoscopy, may reduce the likelihood of misdiagnosis, and improve treatment and prognosis.

\section{Declarations}

\section{Acknowledgments}

We thank the editors and reviewers for their contributions and thank Mr. Yang Shu for his guidance on statistical analysis.

\section{Funding}

Chongqing Science and Health joint medical research project (8187011078)

\section{Data Availability Statement}

The data that support the findings of this study are available from the corresponding author upon reasonable request. Extra data are available by emailing t_dy@163.com

\section{Author contributions}


Chen Zhang and Wenlong Fu planned the study, monitored its progress, and drafted the manuscript based on comments provided by all authors. In addition, Chen Zhang was responsible for data collection and management, and Wenlong Fu was responsible for the follow-up of children. Chen Zhang and Wenlong Fu contributed equally to this study. Xiaofeng Ma was responsible for the design of identification models. Daiyin Tian designed the study and revised the manuscript. Jihong Dai, Yonggang Li, Xingye Tang, Gang Geng, Ying Li, Ting Yang, Li Yan, Jingyue Liu, Zheng Liu, and Xiaoping Yuan provided guidance with respect to important intellectual content. All authors approved the final version of the manuscript.

\section{Ethics}

Use of the database for this retrospective study was approved and permitted by the Ethics Committee of the Children's Hospital of Chongqing Medical University.

\section{Conflicts of interest}

The authors have no conflicts of interest related to this study.

\section{References}

1 Xu LT, Sun ZF, Li ZJ, Wu LH, Zhang ZY, Yu XQ. Clinical and pathologic characteristics in patients with tracheobronchial tumor: report of 50 patients. Ann Thorac Surg. 1987;43(3):276-278.

2 Kleihues P , Sobin L H . World Health Organization classification of tumors[J]. Cancer, 2015, 88.

3 Ishizumi T, Tateishi U, Watanabe S I, et al. F-18 FDG PET/CT imaging of low-grade mucoepidermoid carcinoma of the bronchus[J]. Annals of Nuclear Medicine, 2007, 21(5):299-302.

4 Yu Y , Song Z , Chen Z , et al. Chinese pediatric and adolescent primary tracheobronchial tumors: a hospital-based study[J]. pediatric surgery international, 2011, 27(7):721-726.

5 Scott K J , Darrow D , Greinwald J H, et al. Endobronchial Tumors in Children: An Uncommon Clinical Entity[J]. Annals of Otology Rhinology \& Laryngology, 2001, 110(1):63-69.

6 Eyssartier E , Ang P , Bonnemaison E , et al. Characteristics of endobronchial primitive tumors in children[J]. Pediatric Pulmonology, 2014, 49(6):E121-E125.

7 Varela P , Pio L, Torre M . Primary tracheobronchial tumors in children[J]. Seminars in Pediatric Surgery, 2016, 25(3):150-155.

8 Varela P , Pio L , Brandigi E, et al. Tracheal and bronchial tumors[J]. Journal of Thoracic Disease, 2016, 8(12):3781-3786.

9 Hongwu W , Jieli Z , Dongmei L, et al. Efficacy of Bronchoscopic Therapies for Bronchial Mucoepidermoid Carcinoma in Children: Results from Six Patients[J]. Tumori Journal, 2015, 101(1):52-56.

10 Le-Tian X , Zhen-Fu S , Ze-Jian L, et al. Tracheobronchial Tumors: An Eighteen-Year Series from Capital Hospital, Peking, China[J]. Annals of Thoracic Surgery, 1983, 35(6):590-596.

11 Techavichit P , Hicks M J , López-Terrada, Dolores H, et al. Mucoepidermoid Carcinoma in Children: A Single Institutional Experience[J]. Pediatric Blood \& Cancer, 2016, 63(1):27-31.

12 Cuestas G, Rodríguez V, Doormann F, Bellia Munzón P, Bellia Munzón G. Tracheobronchial and pulmonary papillomatosis without involvement of the larynx treated with intravenous Bevacizumab in a child. Arch Argent Pediatr. 2019;117(1):e72-e76.

13 Jindal A, Bal A, Agarwal R. Inflammatory myofibroblastic tumor of the trachea in the pediatric age group: case report and systematic review of the literature. [J]. Journal of Bronchology \& Interventional Pulmonology, 2015, 22(1):58-65.

14 Butrynski J E , D'Adamo D R , Hornick J L , et al. Crizotinib in ALK-Rearranged Inflammatory Myofibroblastic Tumor[J]. New England Journal of Medicine, 2010, 363(18):1727-1733.

15 Takeuchi K, Soda M , Togashi Y, et al. Pulmonary Inflammatory Myofibroblastic Tumor Expressing a Novel Fusion, PPFIBP1-ALK: Reappraisal of Anti-ALK Immunohistochemistry as a Tool for Novel ALK Fusion Identification[J]. Clinical Cancer Research, 2011, 17(10):3341-3348.

16 Giannini L , Incandela F , Bresciani L , et al. Surgical treatment of primary tracheal tumors in children and adolescents[J]. Pediatric Medicine, 2019, 2:3-3.

17 Rojas $\mathrm{Y}$, Shi $\mathrm{YX}$, Zhang W, et al. Primary malignant pulmonary tumors in children: a review of the national cancer data base[J]. Journal of Pediatric Surgery, 2015, 50(6):1004-1008.

18 Jaramillo S, Rojas Y, Slater B J , et al. Childhood and adolescent tracheobronchial mucoepidermoid carcinoma (MEC): a case-series and review of the literature[J]. Pediatric Surgery International, 2016, 32(4):417-424.

19 Ferguson, MK, Landreneau, etc. Long-term outcome after resection for bronchial carcinoid tumors.[J]. European journal of cardio-thoracic surgery, 2000, 18(2):156-161. 
20 Romão RL, de Barros F, Maksoud Filho JG, et al. Malignant tumor of the trachea in children: diagnostic pitfalls and surgical management.[J].Journal of pediatric surgery,2009,44(11):e1-4.

21 Molina J R, Aubry M C , Lewis J E, et al. Primary salivary gland-type lung cancer : Spectrum of clinical presentation, histopathologic and prognostic factors[J]. Cancer, 2007, 110(10):2253-2259.

22 Song Z , Liu Z, Wang J , et al. Primary tracheobronchial mucoepidermoid carcinoma - a retrospective study of 32 patients[J]. world journal of surgical oncology, 2013, 11(1):62.

$23 \mathrm{Ke} \mathrm{M}$, Fenghao S, Xiaodong $Y$, et al. Prognosis of patients with primary malignant main stem bronchial tumors: 7,418 cases based on the SEER database[J]. OncoTargets and Therapy, 2018, Volume 11:83-95.

24 Al-Qahtani A R , Lorenzo M D , Yazbeck S . Endobronchial tumors in children: Institutional experience and literature review[J]. journal of pediatric surgery, 2003, 38(5):733-736.

25 Devang P. Desai, Lauren D. Holinger, Frank Gonzalez-Crussi. Tracheal Neoplasms in Children[J]. Annals of Otology, Rhinology \& Laryngology, 1998,107(9 Pt 1):790-6.

26 Mamoru T, Takahumi Y, Yuki M, et al. A case of tracheal pleomorphic adenoma misdiagnosed as asthma[J]. Oxford Medical Case Reports, 2019, 11(2019):457-460.

\section{Figures}

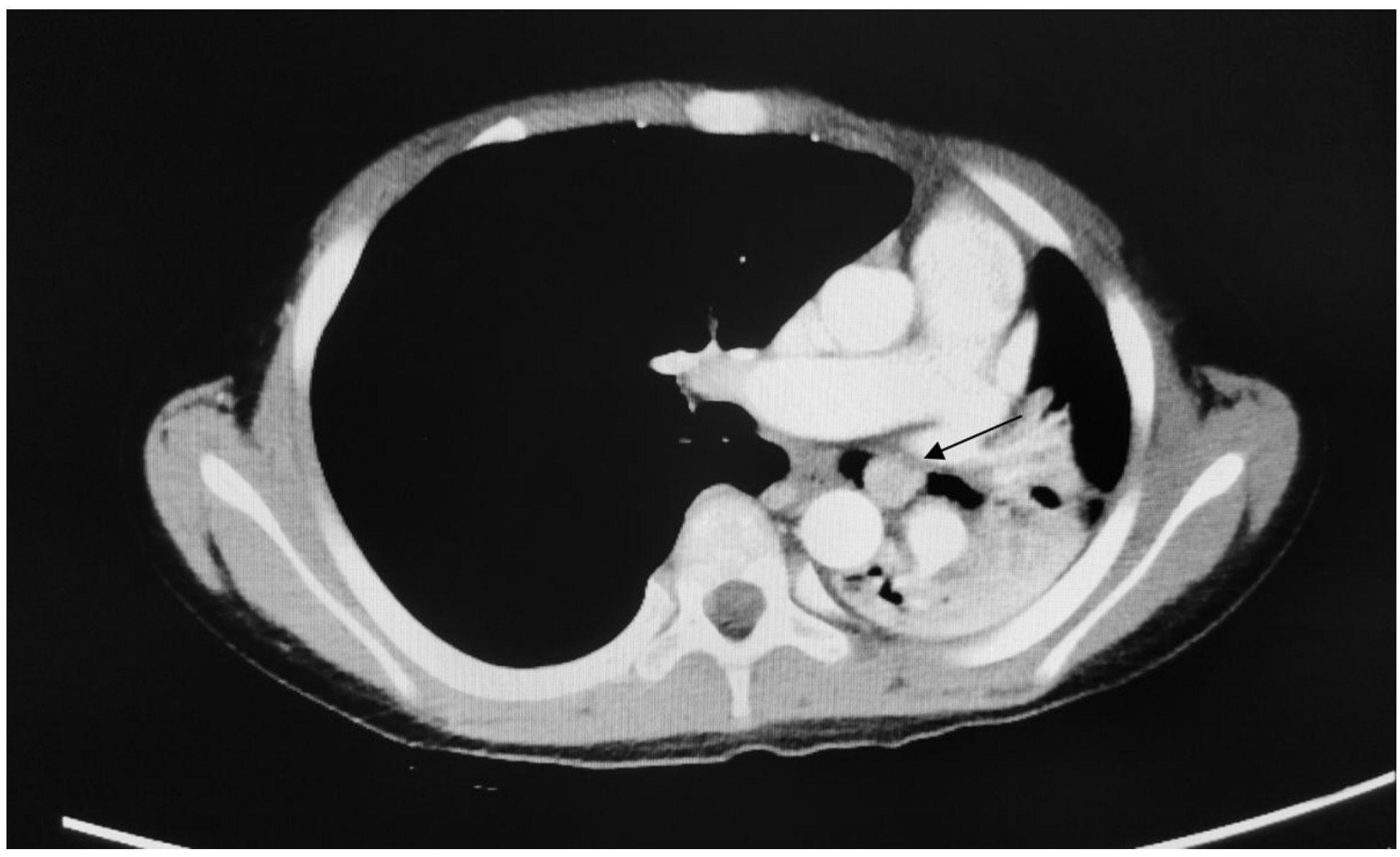

\section{Figure 1}

Preoperative computed tomography (CT) scan of patient no. 6, showing a lesion located in the left main stem bronchus (black arrow), obstructing the distal bronchus, as well as atelectasis of the left upper lung. 


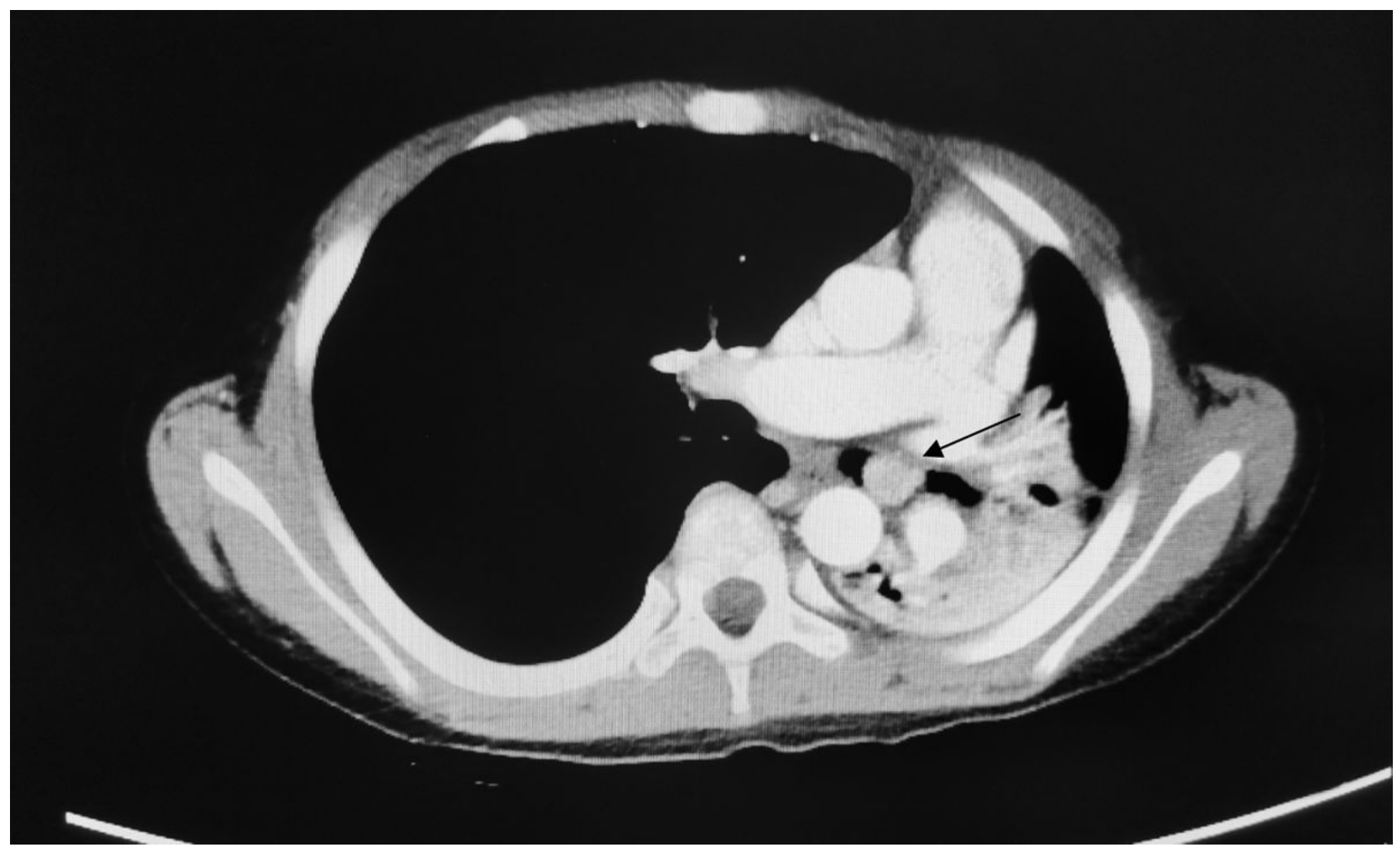

Figure 1

Preoperative computed tomography (CT) scan of patient no. 6, showing a lesion located in the left main stem bronchus (black arrow), obstructing the distal bronchus, as well as atelectasis of the left upper lung. 

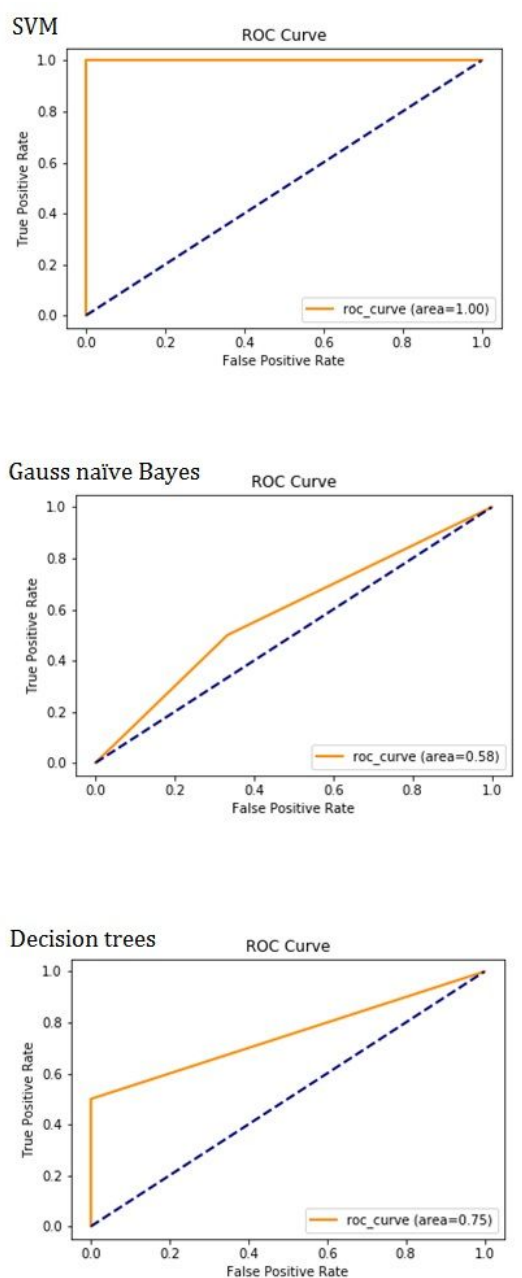

\section{Figure 2}

ROC curve for the three models; the area under the ROC curve (AUC) of the SVM is 1. 

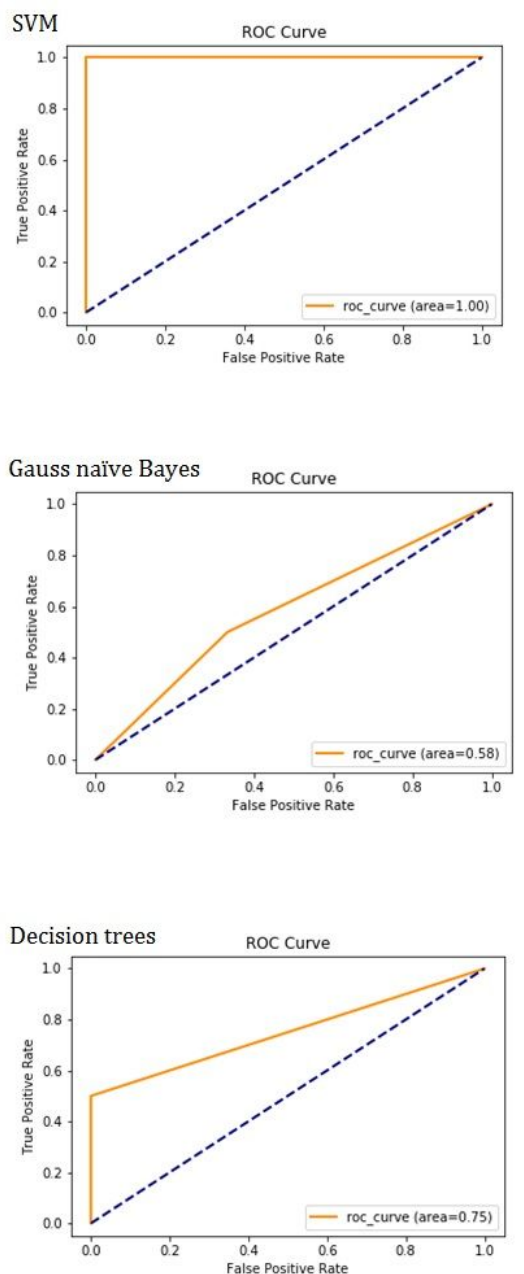

Figure 2

ROC curve for the three models; the area under the ROC curve (AUC) of the SVM is 1. 